\title{
Application of phytoseiid mites for whitefly control on roses in the North-West of Russia
}

\author{
Ekaterina Kozlova $^{1 *}$, Vladimir Moor ${ }^{2}$, and Lidiya Krasavina ${ }^{1}$ \\ ${ }^{1}$ All-Russian Institute of Plant Protection, St.-Petersburg, Russia \\ ${ }^{2}$ Greenhouse Farm «Vyborzhets», Leningrad Area, Russia
}

\begin{abstract}
Predatory mites Amblyseius swirskii and Neoseiulus cucumeris are considered as effective biocontrol agents against whitefly and thrips in indoors on vegetable crops. Our goal was to assess the effect of these predatory mites on whitefly density on roses indoors in the North-West of Russia. Result showed that the dynamics of the pest population is affected not only by the predator release rate, but also by the time between introductions and their frequency. There was no difference between two species, except one case, when temperatures had risen above $27^{\circ} \mathrm{C}$ and consequently $A$. swirskii had a bigger impact on whiteflies than $N$. cucumeris.
\end{abstract}

\section{Introduction}

The whitefly is one of the dangerous pests for the greenhouse roses, which are grown year-round in the North-West of Russia. The control of whitefly population is challenging because of intensive cultivation on hydroponics and consequently high speed of arthropod development under these conditions. Full disinfection and disinfestation of greenhouses with plants replacing is only possible once in every $4-5$ years, creating conditions for pest accumulation. In general, when using the intensive rose cultivation technology, the number of treatments with pesticides can reach up to 20-25 times.

Whitefly parasitoids Encarsia formosa, Eretmocerus mundus and E. eremicus are recommended for roses, but are ineffective in the North-West, as they demand intensive light and high temperatures. Mirid bugs Macrolophus pygmaeus and Nesidiocoris tenuis, are not economically profitable as live insecticide in mass production.

Predatory mite Amblyseius swirskii is also recommended as natural enemy of whiteflies. This species is originated from the Mediterranean region [1]. It can consume mites, thrips, whiteflies, Lepidoptera and Diptera eggs, plant pollen [1, 2, 3, 4], as well as honeydew in the absence of other food [5]. The list of host plants, on which the predator was observed, is also wide and includes fruit crops, vegetables, and cotton. Efficiency of $A$. swirskii as biocontrol agent is closely connected with its ability to breed well on such plants as sweet pepper [6] and cucumber [7].

There are no studies which are confirming the ability of $A$. swirskii to reproduce well on roses. For instance, Chow A., et al (2010) reported that the predator density does not rise on

\footnotetext{
* Corresponding author: kategen vizr@mail.ru
} 
roses. For effective control of thrips, A. swirskii must be released monthly with a consumption rate of 670 mites per 1 sq.m [8]. In general, there is no information about any phytoseiid mites that could control successfully whiteflies on roses.

In our studies, we compared the efficacy of $A$. swirskii with another generalist predator - N. cucumeris, which is cheaper in mass rearing as biocontrol agent than A. swirskii [2].

Comparative studies of these two species on roses have not been performed. There are data about efficacy of these two species on sweet pepper against thrips in the Netherlands [6] and Florida [9]. Based on the results, it was concluded that A. swirskii is more effective than N. cucumeris. However, in studies by Arthurs S. et al. (2009) it is noted that prey consumption and oviposition do not differ between the two species, and the higher efficiency of $A$. swirskii is apparently associated with high - up to $40^{\circ} \mathrm{C}$ - summer temperatures in these regions, which are relatively well tolerated by A. swirskii but are extreme for $N$ cucumeris [9]. In studies by Bolckmans K., et al. (2005) it is also noted that in Southern Europe the use of $N$. cucumeris is very effective in winter, but in summer its efficacy decreases sharply, which, according to the authors, is associated with high temperature in combination with low humidity [6].

\section{Materials and methods}

Our research was planned to be carried out in the North-West of Russia (Leningrad Oblast, Vyborg district) in LLC «Agroalliance» where the maximum temperature in the summer period, even on sunny days, in the greenhouse usually does not exceed $30^{\circ} \mathrm{C}$, and on average amounts to $24-26^{\circ} \mathrm{C}$ with humidity not below $65 \%$. These are optimal conditions for N. cucumeris, which should have a positive effect on its effectiveness.

Observations were performed on Avalanche Peach roses. Pest counts were carried out once every 10 days. The amount of adult whiteflies per leaf was taken into account. Leaves were taken from 3 layers: from the lower layer at the level of the lower part of the factory, the middle layer at the level of the base of the bush, and the upper layer at the level of the upper peduncle leaves with formed buds. The interval between test bushes was 4 meters. The total number of test bushes in each group is 38, the plot area for each group is 302 sq.m. The introduction of predatory mites was carried out once in 7-20 days. Release was performed by scattering the filler with predators on a substrate at the base of the bushes. The distance between the points is also 4 meters, each subsequent application was offset from the previous one by 1 meter.

Since, as already noted, there is no information on the use of $A$. swirskii on roses against whiteflies, when determining the predator application rate, we focused on application rates that turned out to be effective when using the predator on cucumbers against whiteflies and on roses against western flower thrips. On cucumbers, to control whitefly and thrips, onetime application of predatory mites directly to plants with a filler was used at the beginning of the experiment with a release rate of 75 specimen per 1 sq.m. [7]. On roses, to control the thrips population, predators were introduced in a sachet, once a month, normally 670 individuals per 1 sq.m. [8]. It was decided to increase the mite release rate by 1.5 times, to 993 mites per 1 sq.m. compared to the rate recommended by A. Chow, et al (2010) against thrips, and subsequently adjust it depending on the observed situation and the need for research. To correctly compare the effect of two species of predators on the number of whiteflies, two plots were selected that did not differ in the number of pests on plants. The rate of introduction of mites was the same as well. Comparison of changes in the number of pests both between groups and between count dates was carried out using Student's t-test. 


\section{Results}

Observation of the pest population and introduction of predatory mites A. swirskii and $N$. cucumeris began in late April and lasted for 6.5 months, until mid-November.

The average number of whiteflies per leaf did not differ significantly and varied from 0.36 to 0.42 adults per leaf at the first count (April 25) at experimental plots intended for introduction of $A$. swirskii and N. cucumeris (Fig. 1).

It was decided to introduce the initial number of mites in parts, instead of one-time introduction. Half of the above norm was introduced at the first count of the pest on April 25 and another half - after 7 days. After that, on the 17th day of the experiment (May 11), in the group of $N$. cucumeris the number of whiteflies decreased significantly (4.8 times), and in the group of $A$. swirskii it remained unchanged. However, 20 days later (May 24) the amount of the pest increased by 4.6 and 4.8 times from baseline for $A$. swirskii and $N$. cucumeris, respectively. In this regard, on May 24, an additional introduction of predators was carried out at the same rate as for the two initial introductions (993 mite specimen per 1 sq.m.).

In the next month (June), the predators were also introduced 3 times, but with the same time interval of 10 days, 662 mites per 1 sq.m. In both cases, the number of pests decreased during this month. In the group with $N$. cucumeris the decrease was insignificant $(\mathrm{P}=0.05)$, while in the group with $A$. swirskii a significant decrease by 1.5 times was observed $(\mathrm{P}=$ $0.05)$. However, there were no significant differences between the options. Due to the stable situation and the low number of pests in June, the next introduction of predatory mites was not carried out for a long time, more than two weeks. An assessment of the state of the pest population at the beginning of the second decade of July showed that such a long period between predator introductions is not optimal. By July 10, the pest population increased by 2.5 and 2.3 times in the groups of $N$. cucumeris and A. swirskii, respectively. As a result, the rate of introduction of predators was increased by $25 \%$, to 828 specimen per 1 sq.m. Within a week after this, the pest population did not increase significantly, but after another week it increased by 2.3 and 2.8 times in the groups of $N$. cucumeris and A. swirskii, respectively. Another introduction of predators in the same amount of 828 specimen per 1 sq.m. was carried out. Thus, in July, only 2 introductions of predators were carried out, and their total number is less than in June by $20 \%$. As a result, the growth of whitefly numbers was significant and amounted to $83 \%$ and $92 \%$ in the groups of $N$. cucumeris and $A$. swirskii, respectively.

To find out the reason for such an extreme increase in the pest population, i.e. the insufficient number of predators, the frequency of introduction, or the interval between introductions, it was decided to increase the general rate of introduction of predators in August to the release rate used in May and June, while maintaining the frequency of introduction used in July ( 2 times) with an interval of 2 weeks. With this use of predators, the number of whiteflies continued to increase and reached an average of 29.2 and 22.8 adults per leaf in groups of $N$. cucumeris and A. swirskii, respectively, which is $62 \%$ and $33 \%$ greater than in late July. It should be noted that despite the significant number of whiteflies in both cases, the increase of pest amount was 1.7 times slower when using the $A$. swirskii mite. Also in late August, the number of whiteflies in this group is significantly lower than in the group of $N$. cucumeris $(\mathrm{P}=0.05)$.

Due to such a high number of pests, on August 31 Admiral (100g/L pyriproxyfen) insecticide (Silvit Gold (0.08\%) + Admiral (0.05\%)) was used. The use of the insecticide reduced the number of whiteflies by 5.5 times in both cases.

Since an increase in the monthly rate of introduction of predators in August without changing the pattern of their application did not inhibit the growth of the pest, it was decided to increase the number of applications in September to 4 times. Predatory mites 
were introduced weekly in the amount of 662 specimen per 1 sq.m. The monthly rate of introduction of mites in September also increased and amounted to 2,649 specimen per 1 sq.m. As a result, the number of whiteflies during the month decreased by more than 2.5 times, to 1.54 and 1.64 adults per leaf, in groups of $N$. cucumeris and A. swirskii, respectively.

In October, the total monthly rate of introduction of entomophages was reduced to 1,324 specimen per 1 sq.m., but the frequency of introduction of 4 times a week, as in September, was maintained. Whitefly numbers continued to decrease to 0.32 and 0.59 adults per leaf, in groups of $N$. cucumeris and A. swirskii, respectively.

The differences between the options at $\mathrm{P}=0.05$ in both September and October were not significant.

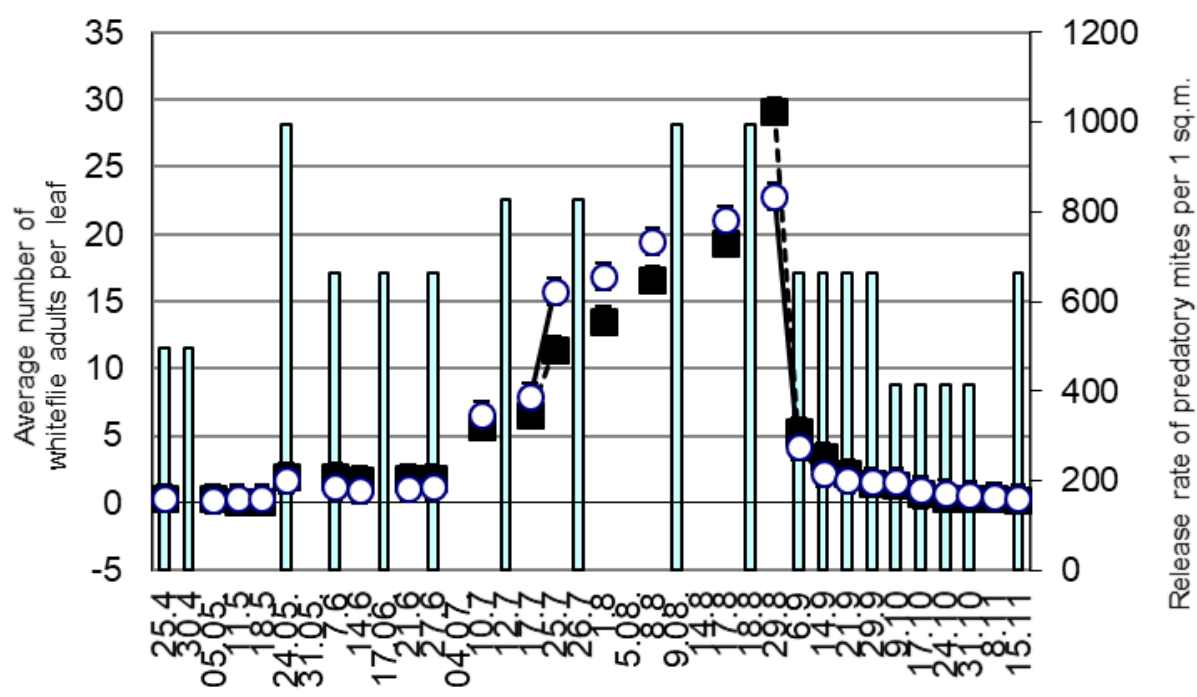

Fig. 1. The change in the number of whiteflies after release of predatory mites

\section{Discussion and Conclusion}

The obtained results of the pest dynamics by months show that the change in its number is affected not only by the number of predators used, but also by the frequency of their introduction and the time interval between applications. This is confirmed by comparison of the pest dynamics for different options of predator use. In May and June, the monthly rates of predator introduction were the same, but in May there was a significant increase in the number of whiteflies after a long 20-day interval between mite introductions. In June, predators were introduced evenly every 10 days and whitefly growth was not observed. As a result, in late June, the pest population was lower than in late May. In July and August, the rates of predator introduction were different (1.2 times higher in August), but the frequency of use was the same (2 times a month), and the pest growth was significant for both months $(\mathrm{P}=0.05)$. In September and October, with a weekly introduction of predators, a steady decrease in the number of whiteflies was observed despite the fact that the total number of predators in October was 2 times lower than in September. Thus, a long (more than 10 days) interval between predator introductions leads to an increase in the number of whiteflies. This suggests that both species of predatory mites do not breed on the rose culture when used against greenhouse whiteflies. Significant differences in the influence of A. swirskii and N. cucumeris on the dynamics of whitefly population were observed only in 
late August against the background of the maximum number of pests for the entire observation period. The lower amount of whiteflies in the group of $A$. swirskii can be explained by two types of thermal preferendum. Despite the fact that the range of temperatures optimal for development of both species lies within $20^{\circ} \mathrm{C}$ to $32^{\circ} \mathrm{C}$, studies of the effect of temperature on the development of the two species demonstrate differences that can affect their effectiveness as well. The population growth rate of A. swirskii is higher at $25^{\circ} \mathrm{C}(\mathrm{r}=0.1353)$ [10] than that of $N$. cucumeris $(\mathrm{r}=0.075)$. In addition, A. swirskii is still quite effective at temperatures above $32^{\circ} \mathrm{C}$, in contrast to $N$. cucumeris, which is depressed at such temperatures. Conversely, N. cucumeris has a higher coefficient of population growth at temperatures below $20^{\circ} \mathrm{C}$. The rate of development of $N$. cucumeris at $15^{\circ} \mathrm{C}$ reaches $\mathrm{r}=0.05$, while the population of $A$. swirskii is degraded (r=-0.0022) [10]. The results of our studies demonstrate the absence of accumulation of mites of both species, but the temperature probably affected the life expectancy and voracity of introduced predators, which in turn was reflected in the dynamics of pest extermination.

The overall results of the study show that under the climatic conditions of the NorthWest of Russia, the effect of two species of predatory mites on the dynamics of whiteflies does not significantly differ with the application rates used in our observations. Since the cost of $N$. cucumeris is lower than that of $A$. swirskii, it may be more profitable. It is necessary to take into account not only the cost of entomophages but also their effectiveness in changing climatic conditions when choosing a strategy to control whiteflies. Thus, A. swirskii can also be used during summertime with temperatures above $27^{\circ} \mathrm{C}$.

\section{References}

1. Swirski E., Amitai S., Dorzia N. Israel J. Entomol, 4, 146-155 (1969) http://www.entomology.org.il/sites/default/files/pdfs/IJE-1969-Swirski.pdf

2. McMurtry J.A., Croft B.A. Ann. Rev. Entomology, 42, 291-321 (1997) http://doi.org/ /10.1146/annurev.ento.42.1.291

3. Ragusa S., Swirski E. Israel J. Entomol. 10, 93-103 https://www.cabdirect.org/cabdirect/abstract/19760535981

4. Hoda F. M., El-Naggar M. E., Taha A. H., Ibrahim G. A. Bull. Soc. Ent. Egypt. 66, 113-116 (1986)

5. Ragusa S., Swirski, E. Entomophaga. 22, 4, 383-392 http://doi.org/10.1007/BF02373263

6. Faucher Delisle Julie Évaluation de suppléments alimentaires pour deux espèces d'acariens prédateurs, Amblyseius swirskii et Neoseiulus cucumeris (Acari: Phytoseiidae) pour l'optimisation du contrôle biologique du thrips des petits fruits (Frankliniella occidentalis) en serriculture. Dissertation, Université de Montréal (2014) https://papyrus.bib.umontreal.ca/xmlui/handle/1866/10740

7. Calvo F. J., Bolckmans K., Belda J. E. BioControl. 56, 185-192 (2011) http://doi.org/ 10.1007/s10526-010-9319-5

8. Chow A, Chau A \& Heinz KM. Biol. Control. 53, 188-196 (2010) http://doi.org/ 10.1016/j.biocontrol.2009.12.008

9. Arthurs S., McKenzie C.L., Chen J, Dogramaci M., Brennan M., Houben K., Osborne L. Biological Control, 49, 91-96 (2009) http://doi.org/10.1016/j.biocontrol.2009.01.002

10. Lee, H.-S. et Gillespie, D.R. Exper. Appl. Acarol., 53, 17-27 (2011) http://doi.org/10.1007/s10493-010-9385-5 